\title{
Safety effect of fermented oyster extract on the endocrine disruptor assay in vitro and in vivo
}

\author{
Hyesook Lee ${ }^{1,2}$, Hyun Hwangbo ${ }^{1,2}$, Seon Yeong Ji, ${ }^{1,2}$, Seyeon Oh ${ }^{3}$, Kyung-A Byun ${ }^{3,4}$, Joung-Hyun Park ${ }^{5}$, \\ Bae-Jin Lee ${ }^{5}$, Gi-Young Kim ${ }^{6}$, Yung Hyun Choi ${ }^{1,2, *}$ \\ ${ }^{1}$ Department of Biochemistry, College of Korean Medicine, Dong-eui University, Busan 47227, Korea \\ ${ }^{2}$ Anti-Aging Research Center, Dong-eui University, Busan 47340, Korea \\ ${ }^{3}$ Functional Cellular Networks Laboratory, College of Medicine, Department of Medicine, Graduate School and Lee Gil Ya Cancer and Diabetes \\ Institute, Gachon University, Incheon 21999, Korea \\ ${ }^{4}$ Department of Anatomy \& Cell Biology, Gachon University College of Medicine, Incheon 21936, Korea \\ ${ }^{5}$ Ocean Fisheries \& Biology Center, Marine Bioprocess Co., Ltd., Busan 46048, Korea \\ ${ }^{6}$ Department of Marine Life Science, Jeju National University, Jeju 63243, Korea
}

\begin{abstract}
Oyster (Crassostrea gigas) is a marine bivalve mollusk widely distributed in coastal areas, and have been long widely used in industrial resources. Several studies demonstrated that fermented oyster (FO) extract attribute to bone health, but whether administration of FO play as an endocrine disruptor has not been studied. Therefore, in the present study, we investigated the effect of $\mathrm{FO}$ on the endocrine system in vitro and in vivo. As the results of the competitive estrogen receptor (ER) and androgen receptor (AR) binding affinities, FO was not combined with ER- $\alpha$, ER- $\beta$, and AR. However, 17 $\beta$-estradiol and testosterone, used as positive control, were interacted with ER and AR, respectively. Meanwhile, oral administration of $100 \mathrm{mg} / \mathrm{kg}$ and $200 \mathrm{mg} / \mathrm{kg}$ of FO doesn't have any harmful effect on the body weight, androgen-dependent sex accessory organs, estrogen-dependent-sex accessory organs, kidney, and liver in immature rats. In addition, FO supplementation has no effect on the serum levels of luteinizing hormone $(\mathrm{LH})$, follicle stimulating hormone $(\mathrm{FSH})$, testosterone, and 17ß-estradiol. However, the relative weight of androgen- and estrogen-dependent organs were significantly increased by subcutaneously injection of $4.0 \mathrm{mg} / \mathrm{kg}$ of testosterone propionate (TP) and by orally administration of $1.0 \mu \mathrm{g}$ of $17 \mathrm{a}$-ethynyl estradiol (EE) in immature male and female rats, respectively. Furthermore, TP and EE administration markedly decreased the serum LH and FSH levels, which are similar those of mature Sprague-Dawley (SD) rat. Furthermore, the testosterone and 17 3 -estradiol levels were significantly enhanced in TP and EE-treated immature rats. Taken together, our findings showed that FO does not interact with ER and AR, suggesting consequentially FO does not play as a ligand for ER and AR. Furthermore, oral administration of FO did not act as an endocrine disruptor including androgenic activity, estrogenic activity, and abnormal levels of sex hormone, indicating FO may ensure the safety on endocrine system to develop dietary supplement for bone health.
\end{abstract}

Keywords: androgen, endocrine disruptor, estrogen, fermented oyster (FO), reproductive toxicity

Received: Sep 17, 2021 Revised: Sep 28, 2021 Accepted: Sep 28, 2021

${ }^{*}$ Corresponding author: Yung Hyun Choi

Department of Biochemistry, College of Korean Medicine, Dong-eui University, Busan 47227, Korea

Tel: +82-51-890-3319, Fax: +82-51-890-3333, E-mail: choiyh@deu.ac.kr

This is an Open Access article distributed under the terms of the Creative Commons Attribution Non-Commercial License (http://creativecommons.org/licenses/by$\mathrm{nc} / 4.0 /$ ) which permits unrestricted non-commercial use, distribution, and reproduction in any medium, provided the original work is properly cited.

Copyright $\odot 2021$ The Korean Society of Fisheries and Aquatic Science 


\section{Introduction}

Body growth is controlled by environmental factors and genetic condition, which interact to form a complex process across all organs (Argente, 2016). A growth delay occurs when a child is growing at the poor or abnormal rate for their age, and can have a wide variety of causes, including a family history of short stature, constitutional growth delay, growth hormone deficiency, hypothyroidism and poor nutrition (Argente, 2016; Rosenfeld, 2003). Up to now, several therapies are used to improve height growth, such as human growth hormone (hGH) replacement, insulin like growth factor-1 (IGF-1) treatment, and bone lengthening surgery (Argente, 2016; Lee et al., 2020a). Among them, hGH replacement therapy has been prescribed to primate for height growth for more than fifty years (Souza \& Collett-Solberg, 2011). Recently, the growing interesting in the predicted final height and socio-economic development often have hGH replacement was carried out children in a normal range who does not correspond to short stature (Argente, 2016; Jeong et al., 2021). The effect of hGH therapy is dose dependent, with lower dosages being less efficacious, whereas too high doses may accelerate growth velocity and stimulate a rapid progression through puberty, possibly limiting final height gain (Kamp et al., 2002; Wit et al., 2002, 2005). In addition, there have been reported that rhGH replacement therapy in children and adolescents caused several side effects including pain at injection site, fever, arthralgia, edema, insulin resistance, and progression of scoliosis (Souza \& Collett-Solberg, 2011). Furthermore, since hGH stimulates cell multiplication, development of neoplasms is a concern (Souza \& Collett-Solberg, 2011). Noteworthy, there are concerns that hGH-treatment may cause precocious puberty, such as prepubertal gynecomastia (Huh et al., 2021). In this regard, there is a growing need to develop new and effective alternative replacements that have low side effects and are safe for the treatment of growth failure.

Oyster (Crassostrea gigas) is a marine bivalve mollusk widely distributed in coastal areas, and have been long widely used in industrial resources in many countries, including Korea, Japan, and China (Xiang et al., 2021; Zhang et al., 2021). Oyster possesses a high nutrient value, because of its abundant microelements, polypeptide, amino acids and other nutrient factors, which can promote immune modulation and prevent inflammatory disease (Xiang et al., 2021). Moreover, several studies demonstrated that oyster components enhanced bone tissue regeneration and prevent osteoclast differentiation due to their high calcium content (Coringa et al., 2018; Lee et al., 2017). In addition, accumulated evidence has demonstrated that fermented oyster (FO) produced by Lactobacillus brevis BJ20 is contributed to bone health (Ihn et al., 2019; Jeong et al., 2019; Lee et al., 2020a, 2020b; Molagoda et al., 2019). There have been reported that FO promotes osteoblast differentiation, leading to bone formation, and prevents ovariectomy-induced osteoclastogenesis (Ihn et al., 2019; Molagoda et al., 2019). Furthermore, Jeong et al. (2019) suggested that FO protect against receptor activator of nuclear factor- $\mathrm{kB}$ ligand-induced osteoclast differentiation. Actually, recent studies established that FO increases body length and enhanced the expression of bone morphogenic proteins in the proximal tibial growth plate (Lee et al., 2020a, 2020b). More recently, there have been demonstrated that supplementation of FO in children with short stature for 24 weeks increase the height, and the effect might be mediated via effects on the bone morphogenic proteins levels (Jeong et al., 2021). However, to date, although there have been established that FO attribute to bone health including promoting osteoblast differentiation, suppression osteoclast differentiation, and increasing heigh, whether administration of FO play as an endocrine disruptor has not been studies. Therefore, the aim of the present study was to investigate the effect of FO on the endocrine system in vitro and in vivo, and to establish the safety for development of dietary supplement for bone health.

\section{Materials and Methods}

\section{Preparation of fermented oyster and chemicals}

FO extract was obtained from Marine Bioprocess (Busan, Korea). In brief, oyster was fermented with L. brevis BJ20, and used FO in the study was the same batch as used that in a previous report (Lee et al., 2020b). 17a-ethynyl estradiol, 17 $\beta$-estradiol, testosterone and testosterone propionate (TP) were obtained from Sigma-Aldrich Chemical (St. Louis, MO, USA). Normal saline was obtained from JW Pharmaceutical, Seoul, Korea). FO and chemicals were dissolved in normal saline.

\section{Fluorescence polarization competition ligand-binding assays}

To evaluate the binding affinity of ligands for estrogen receptor (ER)- $\alpha$ and ER- $\beta$ of FO ( $50 \mu \mathrm{g} / \mathrm{mL}$ to $600 \mu \mathrm{g} / \mathrm{mL})$ were measure using PolarScreen ${ }^{\mathrm{TM}}$ ER- $\alpha$ Competitor Assay kit (catalog No. A15882; Thermo Fisher Scientific, Waltham, MA, USA) and PolarScreen ${ }^{\text {TM }}$ ER- $\beta$ Competitor Assay kit (catalog No. A15890; Thermo Fisher Scientific), in accordance with the manufactur- 
er's instructions. The binding affinity of ligands for androgen receptor (AR) was measured using PolarScreen ${ }^{\mathrm{TM}}$ AR Competitor Assay kit (catalog No. A15880; Thermo Fisher Scientific). $17 \beta$-estradiol $\left(10^{-1}\right.$ to $\left.10^{4} \mathrm{nM}\right)$ and testosterone were used as positive control for the competitive ER binding assay and the comparative AR binding assay, respectively. Fluorescence polarization was detected using fluorescence microplate reader (Beckman Coulter, Brea, CA, USA) at the Core Facility Center for Tissue Regeneration (Dong-eui University, Busan, Korea). Approximate $\mathrm{IC}_{50}$ values were determined by GraphPad Prism Software (GraphPad Software, La Jolla, CA, USA) from competitive binding curves.

\section{Animals}

All animal studies were performed in accordance with Institutional Animal Care and Use Committee of Gachon University. The protocol used this study was reviewed and approved by the Center of Animal Care and Use ethical board of Gachon University (CACU; Approval No.: LCDI-2021-0076). Immature male Sprague-Dawley (SD) rats (18-days old, $\mathrm{n}=24)$, immature female SD rats (18-days old, $\mathrm{n}=24)$, mature male SD rats (9-weeks old, $\mathrm{n}=6$ ) and mature female SD rats (9-weeks old, $n=6$ ) were obtained from Orient Bio (Sungnam, Korea) and housed in a semi-pathogen-free facility with a temperature of temperature, $23 \pm 1{ }^{\circ} \mathrm{C}$, relative humidity of $50 \pm 5 \%$ with $12 \mathrm{~h}$ light/12 $\mathrm{h}$ dark cycles and ad libitum access to food and water. All animals acclimatized for 1 week.

\section{Hershberger bioassay in immature Sprague-Dawley rats}

Hershberger bioassay in immature rats was performed in accordance with the Organisation for Economic Co-operation and Development (OECD) guidelines with modifications (OECD, 2009a; US Environmental Protection Agency, 2021). In brief, immature male SD rats $(30 \pm 5 \mathrm{~g})$ were randomly divided into four groups based on body weight (BW). The rats were orally administered with i) Saline ( $5 \mathrm{~mL} / \mathrm{kg}$; vehicle control, $\mathrm{n}=6)$, ii) FO100 (100 mg of extract FO/5 mL/kg, $\mathrm{n}=6)$, iii) FO200 (200 $\mathrm{mg}$ of extract $\mathrm{FO} / 5 \mathrm{~mL} / \mathrm{kg}, \mathrm{n}=6$ ), and subcutaneously injected with iv) TP (4.0 mg of TP/5 mL/kg; positive control, $\mathrm{n}=6$ ) daily for 10 days. All sample were obtained $24 \mathrm{hr}$ after the last day of test substance administration, and the blood was collected into serum separating tube (Becton Dickinson, Franklin Lakes, NJ, USA), centrifuged at $800 \times \mathrm{g}$ for $20 \mathrm{~min}$ and then transferred the supernatants. The organs were dissected free of fat under anatomy microscope (Olympus Optical, Tokyo, Japan), and weighed.

\section{Uterotrophic bioassay in immature Sprague-Dawley rats}

Uterotrophic bioassay in immature rats was performed in accordance with the OECD guidelines (OECD, 2009b). Immature female SD rats $(32 \pm 5 \mathrm{~g})$ were divided into four groups based on BW. The rats were orally administered daily for 3 days with i) Saline ( $5 \mathrm{~mL} / \mathrm{kg}$; vehicle control, $\mathrm{n}=6$ ), ii) FO100 (100 mg of extract FO/5 mL/kg, $\mathrm{n}=6$ ), iii) FO200 (200 mg of extract FO/5 $\mathrm{mL} / \mathrm{kg}, \mathrm{n}=6$ ), and iv) ethynyl estradiol (EE; $1.0 \mu \mathrm{g}$ of $17 \alpha-\mathrm{EE} / 5$ $\mathrm{mL} / \mathrm{kg}$; positive control, $\mathrm{n}=6$ ). All animals were necropsied $24 \mathrm{hr}$ after the final administration of test substance, and the serum was separated using serum separating tube at $800 \times \mathrm{g}$ for $20 \mathrm{~min}$. The organs were dissected free of fat under anatomy microscope, and weighed.

\section{Hormone assays}

The serum concentrations of luteinizing hormone (LH), follicle stimulating hormone (FSH), testosterone, and $17 \beta$ - estradiol were measured using LH enzyme-linked immunosorbent assay (ELISA) kit (catalog No. ER1123; FineTest, Hubei, China), FSH ELISA kit (catalog No. ER0960; FineTest), testosterone ELISA kit (catalog No. RTC001R; BioVendor Laboratory Medicine, Brno, Czech), and 17 $\beta$ - Estradiol ELISA kit (catalog No. ADI-900-174; Enzo Life Sciences, Farmingdale, NY, USA). All procedures were performed the manufacturer's instructions. In immature SD rats, the hormone levels following by administration of FO or positive controls were compared with that from mature SD rats.

\section{Statistical analysis}

Nonparametric tests were used in this study. The Kruskal-Wallis test was used to determine the significance of differences between the four groups. If a significant difference was confirmed by Kruskal-Wallis, multiple comparisons were performed using Mann-Whitney-U test as a post-hoc test. All experiments were performed in triplicate for each animal, and the results are presented as the mean \pm standard deviation. Statistical analysis was conducted using SPSS version 22 (IBM, Armonk, NY, USA).

\section{Results}

\section{Competitive binding affinity of fermented oyster to estro- gen receptor and androgen receptor}

In vitro fluorescence polarization assays were used to determine the relative ER and AR binding affinities of FO. Fig. 1A showed that $17 \beta$-estradiol, a positive control, was competitive bind to 
(A)

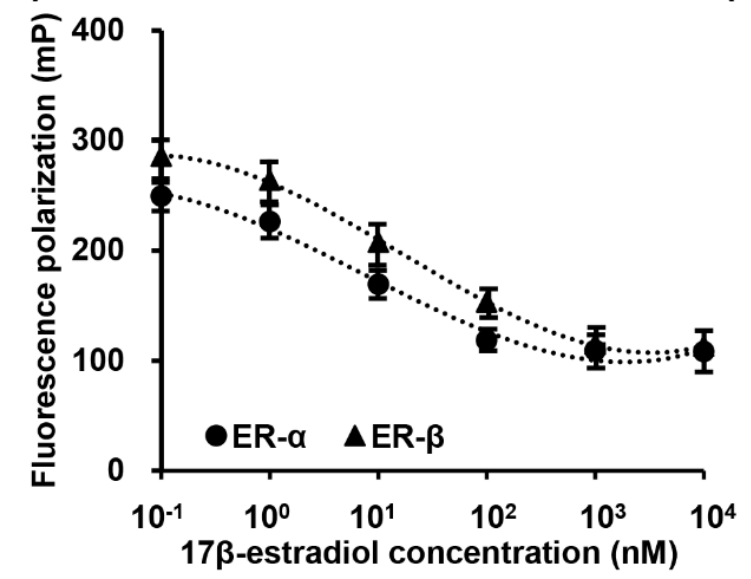

(B)

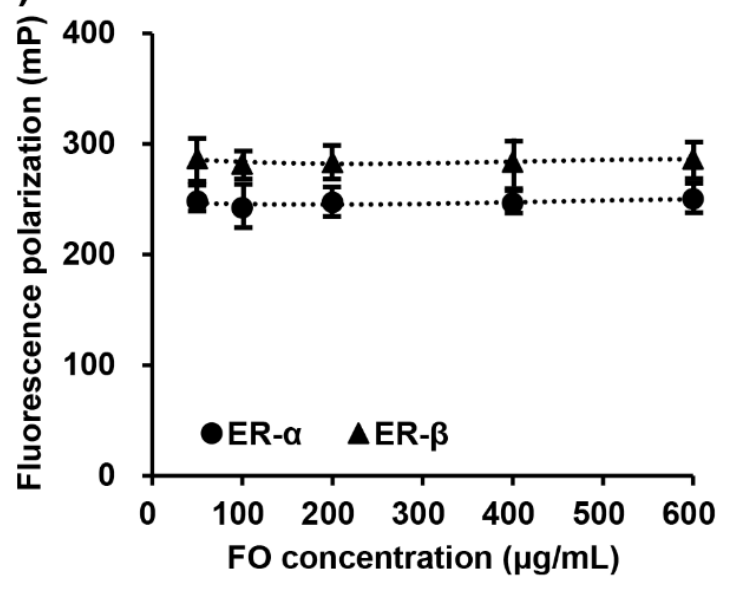

(C)

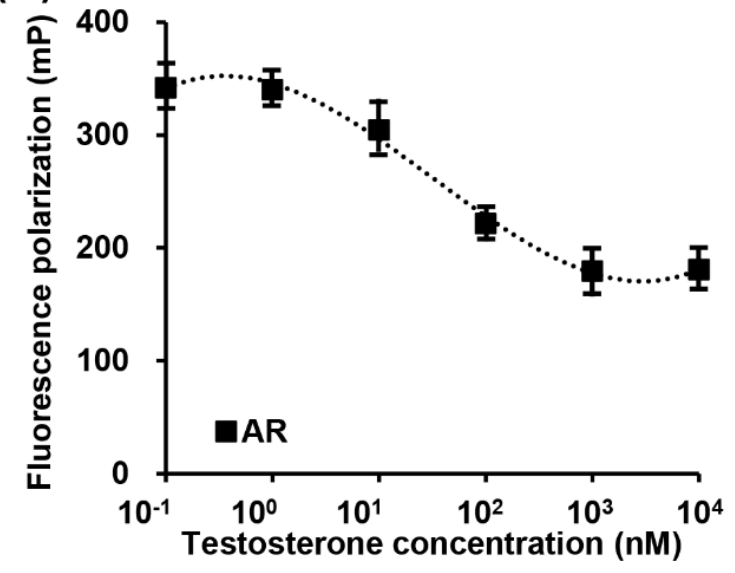

(D)

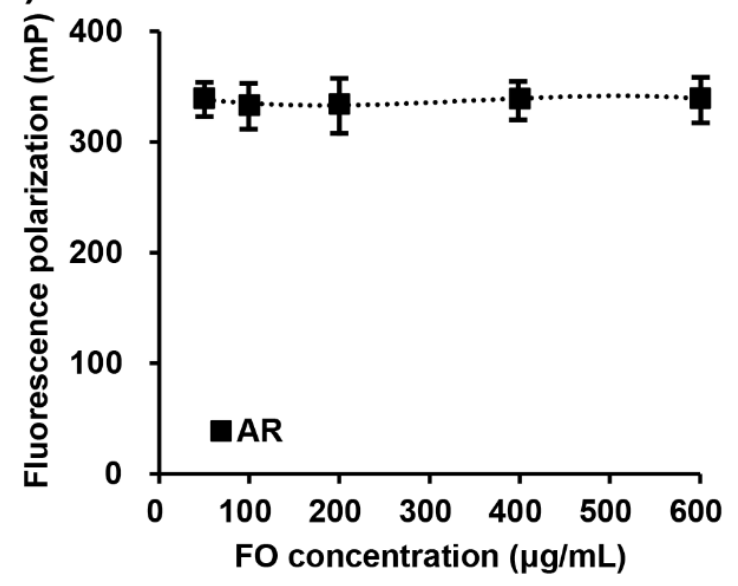

Fig. 1. Comparative estrogen and androgen receptors binding assay of FO. (A) Relative ligand-binding affinity of $17 \beta$-estradiol to $E R-\alpha$ and $E R-\beta$. (B) Relative ligand-binding affinity of FO to ER- $\alpha$ and $E R-\beta$. (C) Relative ligand-binding affinity of testosterone to AR. (D) Relative ligand-binding affinity of FO to AR. FO, fermented oyster extracts; ER- $\alpha$, estrogen receptor- $\alpha$; ER- $\beta$, estrogen receptor- $\beta$; AR, androgen receptor.

ER- $\alpha$ and ER- $\beta$. The $\mathrm{IC}_{50}$ competitive values for $17 \beta$-estradiol on ER- $\alpha$ and ER- $\beta$ binding are approximately $4.61 \mathrm{nM}(1.253$ $\mathrm{mg} / \mathrm{mL})$ and $5.22 \mathrm{nM}(1.421 \mathrm{ng} / \mathrm{mL})$, respectively. However, FO in the concentration range from $50 \mu \mathrm{g} / \mathrm{mL}$ to $600 \mu \mathrm{g} / \mathrm{mL}$ was not combined with ER- $\alpha$ and ER- $\beta$ (Fig. 1B). Meanwhile, testosterone was also competitive bind to $\mathrm{AR}$, and the $\mathrm{IC}_{50}$ value was approximately $22.14 \mathrm{nM}(6.385 \mathrm{ng} / \mathrm{mL})$, while FO had no effect on competitive AR assay (Figs. 1C and D). These results indicated that FO does not interact with $\mathrm{ER}$ and $\mathrm{AR}$, suggesting consequentially FO does not play as ligand for ER and AR.
The effect of fermented oyster on androgenic activity in immature male Sprague-Dawley rats

Fig. 2A showed that no significant differences were observed in BW among the groups in immature male SD rats. Furthermore, the relative weights of liver, kidney, adrenal glands and levator ani muscle were no statistical significance between the groups (Table 1 and Fig. 2H). As shown in Figs. 2B-G, the relative weight of androgen-dependent organs, including seimal vesicle, prostate, Cowper's glands, cavernous body of penis, glans penis and adrenal glands, was significantly increased following by of 4 $\mathrm{mg} / \mathrm{kg}$ of TP injection for 10 days. However, $100 \mathrm{mg} / \mathrm{kg}$ and 200 $\mathrm{mg} / \mathrm{kg}$ of FO-treated groups, the weights of main androgen-de- 
(A)

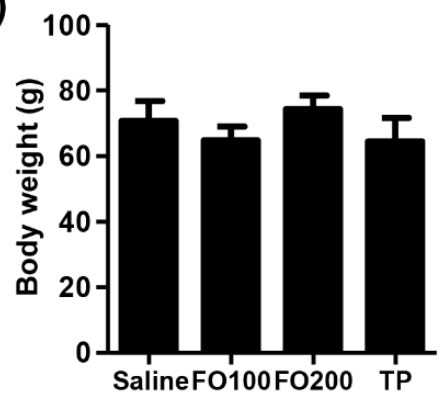

(C)

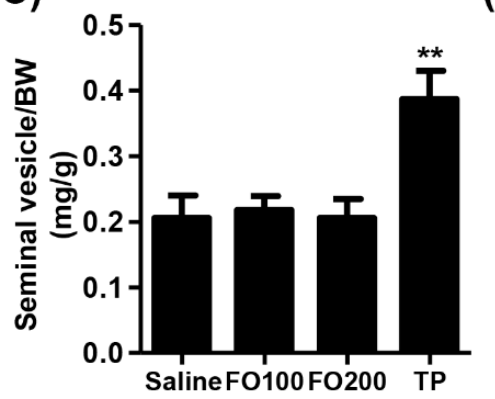

(F)

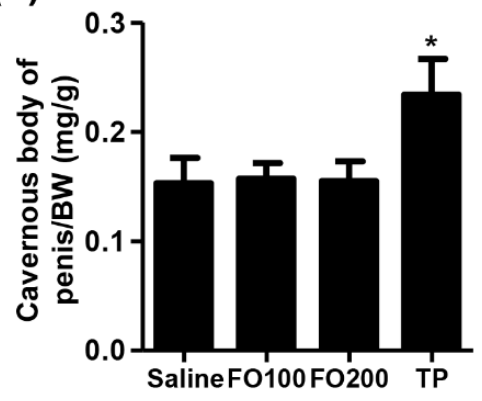

(B)

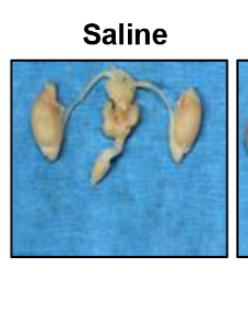

FO 100

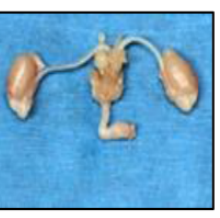

FO 200

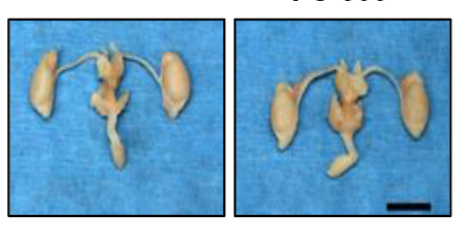

(E)
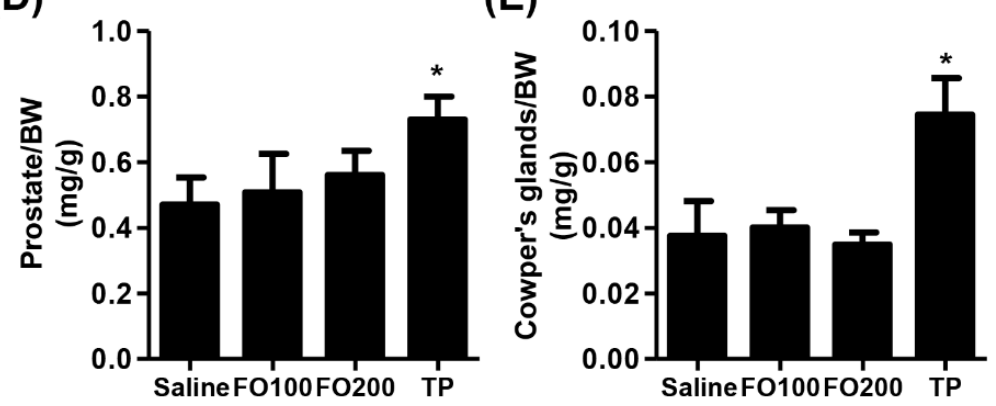

(H)
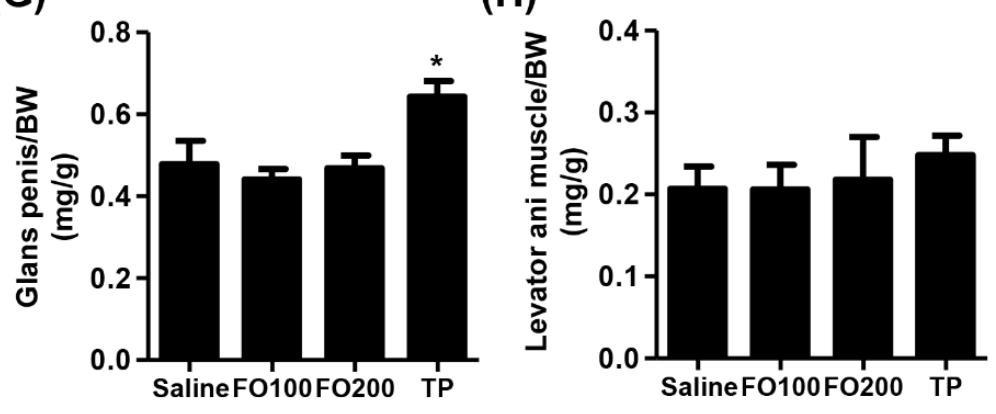

Fig. 2. Changes in the weight of the androgen-dependent organs after 10 days of FO and TP administration in immature rat. (A) 18-days-old male SD rats were weighted after administration of saline, 100 and $200 \mathrm{mg} / \mathrm{kg}$ of FO and TP for 10 days. (B) Image of reproductive organs. Scale bar; $1 \mathrm{~cm}$. (C-H) The weights of seminal vesicle (C), prostate (D), Cowper's glands (E), cavernous body of penis $(F)$, glans penis $(G)$ and levator ani muscle $(H)$ were measured and compared by normalizing them with BW. Data are represented as mean \pm standard deviation. The statistical analyses were conducted by Kruskal-Wallis, multiple comparisons were performed using Mann-Whitney U-test as a post-hoc test between groups. ${ }^{*} p<0.05$ and ${ }^{* *} p<0.01$ compared to the saline group. FO 100, $100 \mathrm{mg} / \mathrm{kg}$ of fermented oyster extracts-administered group; FO 200, $200 \mathrm{mg} / \mathrm{kg}$ of fermented oyster extracts-administered group; TP, 4.0 mg/kg of testosterone propionate-injected group; TP, testosterone propionate; SD, Sprague-Dawley; BW, body weight.

pendent organs were not significantly difference compared with saline group (Figs. 2B-G).

The effect of fermented oyster on estrogenic activity in immature female Sprague-Dawley rats

The change of BW after oral administration of saline, $100 \mathrm{mg} / \mathrm{kg}$ and $200 \mathrm{mg} / \mathrm{kg}$ of FO, and $1 \mu \mathrm{g} / \mathrm{kg}$ of EE for 3 days in immature female SD rats were observed no statistical significance among the groups, although that was slightly increased in EE group
(Fig. 3A). In addition, the relative weights of liver, kidney, and adrenal glands were no statistical significance among the groups (Table 1). Nevertheless, the relative weight of estrogen-dependent organs including ovaries, vagina, uterus and oviduct was markedly enhanced by EE administration (Figs. 3B-E). On the other hand, no significant differences were observed in the relative weights of estrogen-dependent organs between the saline group and FO-administered groups. 
Table 1. Changes in the weight of the body, adrenal glands, liver, and kidney by FO, testosterone and 17-a estradiol in immature male and female rats

\begin{tabular}{|c|c|c|c|c|c|}
\hline Groups & Saline & FO 100 & FO 200 & TP & $\mathrm{EE}$ \\
\hline \multicolumn{6}{|l|}{ Male } \\
\hline $\mathrm{BW}(\mathrm{g})$ & $70.7 \pm 10.5$ & $64.8 \pm 7.3$ & $74.3 \pm 7.2$ & $64.5 \pm 12.4$ & - \\
\hline Adrenal glands/BW $(\mathrm{mg} / \mathrm{g})$ & $0.216 \pm 0.028$ & $0.216 \pm 0.031$ & $0.224 \pm 0.032$ & $0.299 \pm 0.073^{*}$ & - \\
\hline Liver/BW (mg/g) & $59.5 \pm 8.9$ & $60.1 \pm 4.0$ & $62.8 \pm 4.8$ & $60.2 \pm 4.5$ & - \\
\hline Kidney/BW (mg/g) & $8.31 \pm 0.79$ & $8.71 \pm 0.98$ & $8.75 \pm 0.91$ & $9.01 \pm 1.18$ & - \\
\hline \multicolumn{6}{|l|}{ Female } \\
\hline $\mathrm{BW}(\mathrm{g})$ & $28.3 \pm 3.7$ & $28.3 \pm 4.8$ & $28.8 \pm 4.1$ & - & $31.7 \pm 5.0$ \\
\hline Adrenal glands/BW $(\mathrm{mg} / \mathrm{g})$ & $0.330 \pm 0.056$ & $0.357 \pm 0.087$ & $0.351 \pm 0.066$ & - & $0.364 \pm 0.061$ \\
\hline Liver/BW (mg/g) & $42.6 \pm 8.5$ & $53.4 \pm 9.8$ & $44.6 \pm 11.6$ & - & $52.4 \pm 3.3$ \\
\hline Kidney/BW (mg/g) & $9.95 \pm 0.96$ & $9.28 \pm 2.20$ & $9.57 \pm 1.31$ & - & $8.27 \pm 1.85$ \\
\hline
\end{tabular}

Data are represented as mean \pm standard deviation.

The statistical analyses were conducted by Kruskal-Wallis, multiple comparisons were performed using Mann-Whitney U-test as a post-hoc test between groups. p $p<0.05$ compared to the saline group.

FO 100, $100 \mathrm{mg} / \mathrm{kg}$ of fermented oyster extracts-administered group; FO 200, $200 \mathrm{mg} / \mathrm{kg}$ of fermented oyster extracts-administered group; TP, testosterone propionate; $4.0 \mathrm{mg} / \mathrm{kg}$ of testosterone propionate-injected group; EE, ethynyl estradiol, $1.0 \mu \mathrm{g}$ of $17 \mathrm{a}$-estradiol-administered group; BW, body weight.

(A)

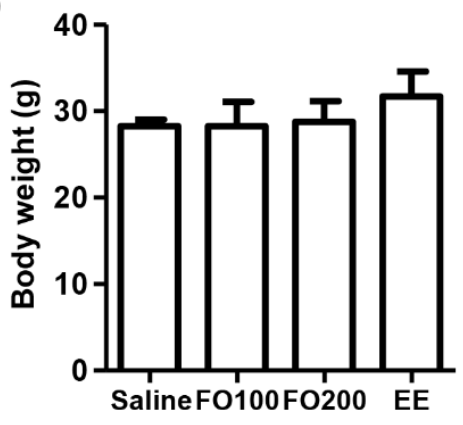

(B)

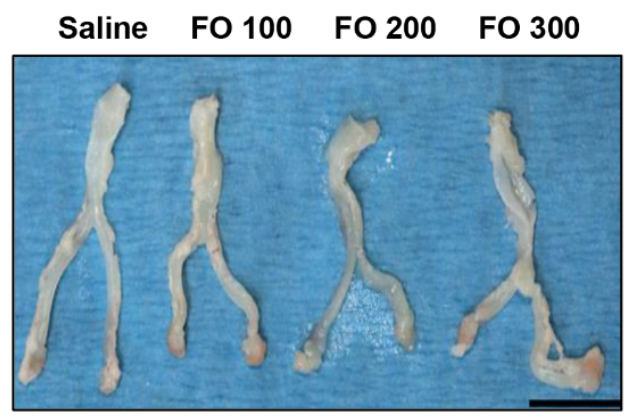

(E)
(C)

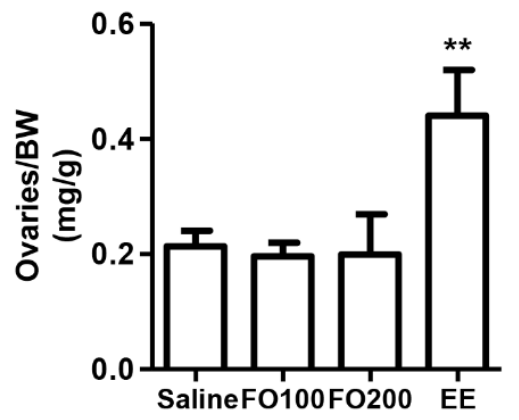

(D)

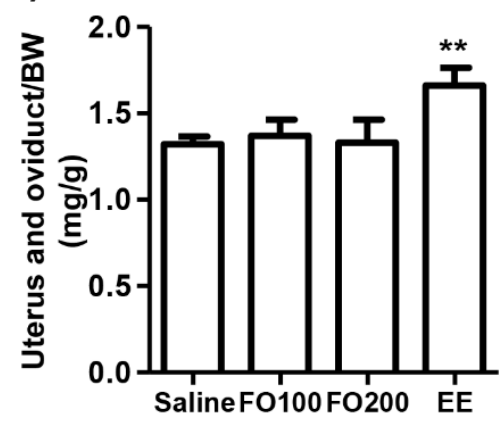

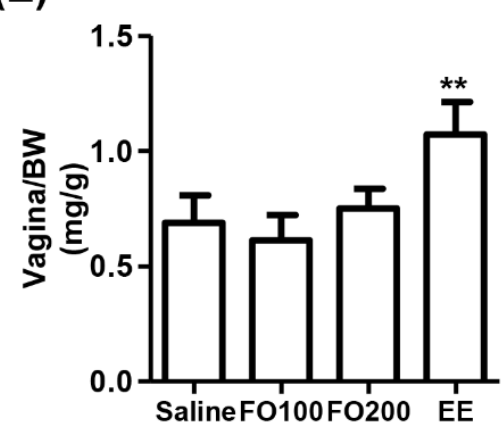

Fig. 3. Changes in the weight of the estrogen-dependent organs after 3 days of FO and EE. (A) 18-days-old female SD rats were measured after oral administration of saline, 100 and $200 \mathrm{mg} / \mathrm{kg}$ of FO and EE for 3 days. (B) Image of reproductive organs of immature female was obtained $24 \mathrm{hr}$ after the last day of saline, FO and EE administration. Scale bar; $1 \mathrm{~cm}$. (C-E) The weights of ovaries (C), uterus and oviduct (D), and vagina (E) were measured and normalized to BW. Data are represented as mean \pm standard deviation. The statistical analyses were conducted by Kruskal-Wallis, multiple comparisons were performed using MannWhitney U-test as a post-hoc test between groups. ${ }^{* *} p<0.01$ compared to the saline group. FO 100, $100 \mathrm{mg} / \mathrm{kg}$ of fermented oyster extracts-administered group; FO 200, $200 \mathrm{mg} / \mathrm{kg}$ of fermented oyster extracts-administered group; EE, ethynyl estradiol, $1.0 \mu \mathrm{g}$ of 17a-estradiol-administered group; SD, Sprague-Dawley; BW, body weight. 
The effect of fermented oyster on the hormone levels in immature Sprague-Dawley rats

Figs. 4A, B, D and E showed that total serum LH and FSH levels in saline-administered immature rats were significantly higher than those in mature rats. Furthermore, no significant differences were observed in total serum LH and FSH levels between the saline group and FO groups in immature rats. However, the levels of serum LH and FSH were markedly decreased by TP injection in immature male rats, which levels similar to that of saline-treated mature male rats. Meanwhile, the levels of serum testosterone in immature male rats were greatly lower than those in mature male rats (Fig. 4C). The testosterone levels were no significantly difference between saline and FO administration groups, whereas the levels significantly enhanced in TP-treated immature male rats (Fig. 4C). Similar to immature male rats, the serum LH and FSH levels were also significantly reduced by orally administered $\mathrm{EE}$ in immature female rats. Additionally, the serum levels of $17 \beta$-estradiol in immature female rats were substantially lower than that in mature female rats (Fig. 4F). These levels were significantly increased by oral administration of EE in immature female rats, but not altered by oral administration of FO.

\section{Discussion}

In the present study, we investigated the effect of FO on the endocrine system in vitro and in vivo. An endocrine-disrupting compound was defined by the U.S. Environmental Protection Agency (EPA) as "an exogenous agent that interferes with synthesis, secretion, transport, metabolism, binding action, or elimination of natural blood-borne hormones that are present in the body and are responsible for homeostasis, reproduction,
(A)

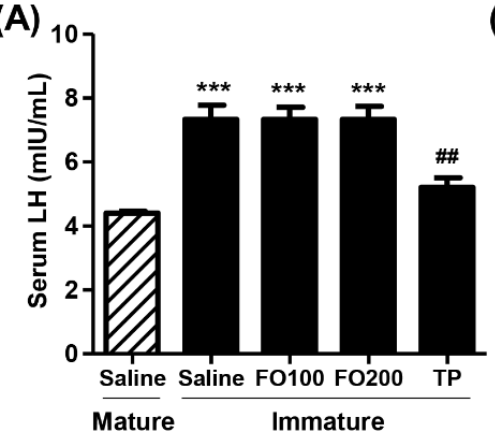

(D)

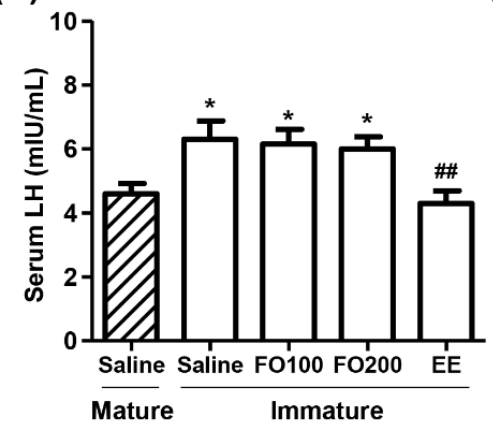

(B)

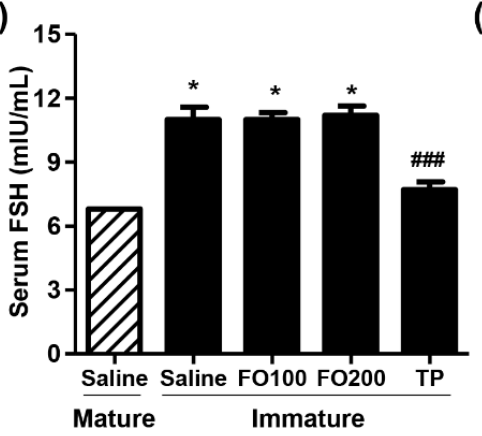

(E)

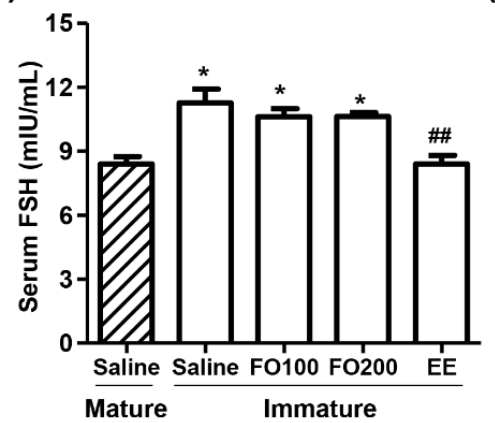

(C)

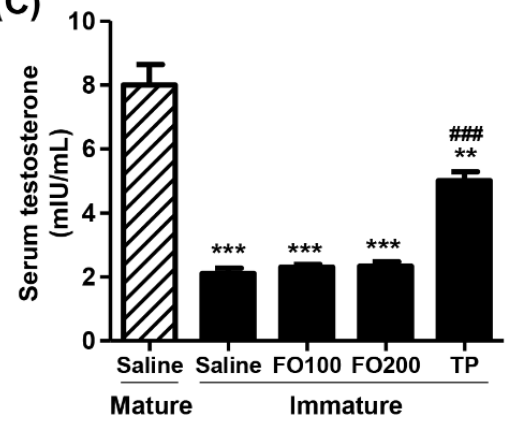

(F)

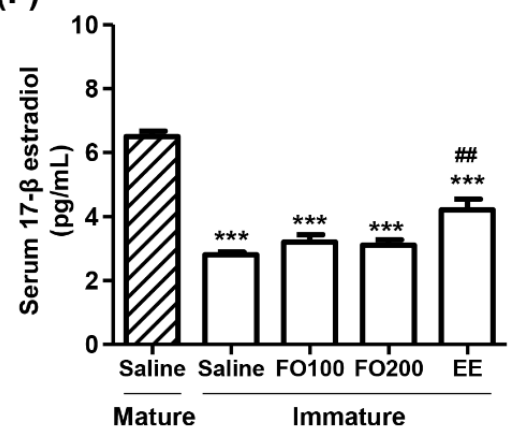

Fig. 4. Hormonal changes after administration of $F O$ and TP or EE in immature male and female rats. (A-C) The levels of $L H$ (A), FSH (B), and testosterone (C) in male serum were measured using ELISA kits. (D-F) The levels of LH (D), FSH (E), and 17- $\beta$ estradiol (F) in female serum were measured using ELISA kits. Data are represented as mean \pm standard deviation. The statistical analyses were conducted by Kruskal-Wallis, multiple comparisons were performed using Mann-Whitney U-test as a post-hoc test between groups. ${ }^{*} p<0.05, * 0<0.01$, and ${ }^{* * * *} p<0.001$ compared to the saline group in mature SD rats. ${ }^{\# \#} p<0.01$ and $^{\# \# \#} p<0.001$ compared to the saline group in immature SD rats. FO 100, $100 \mathrm{mg} / \mathrm{kg}$ of fermented oyster extracts-administered group; FO 200, $200 \mathrm{mg} / \mathrm{kg}$ of fermented oyster extracts-administered group; TP, $4.0 \mathrm{mg} / \mathrm{kg}$ of testosterone propionate-injected group; $\mathrm{EE}, 1.0 \mu \mathrm{g}$ of 17a-estradiol-administered group; LH, luteinizing hormone; FSH, follicle stimulating hormone; ELISA, enzyme-linked immunosorbent assay; SD, Sprague-Dawley. 
and developmental process." (Diamanti-Kandarakis et al., 2009). Endocrine disruptors act through nuclear hormone receptors, ERs, Ars, progesterone receptors, thyroid receptors, and retinoid receptors, among others (Calafat \& Needham, 2007; Diamanti-Kandarakis et al., 2009; Dickerson \& Gore, 2007). In this concern, several methods of examination to evaluate the effect of endocrine system disrupt including sexual maturation were established in accordance of OECD guideline (OECD, 2009a, 2009b; Yamasaki et al., 2003).

Hershberger bioassay that established as OECD test guideline (TG) 441 is a short-term in vivo screening assay in male rats for chemicals that interact with the AR (OECD, 2018). It is based on changes in weight of the accessory tissues of the male reproductive tract in response to androgens and anti-androgens in animal models where endogenous androgens are minimal as a result of castration or because the animals are immature (OECD, 2018). According to OECD TG441, the rat model utilizes the weights of five androgen-dependent sex accessory tissues, including ventral prostate, seminal vesicles, levator ani plus bulbocavernosus muscles, Cowper's glands and glans penis. Furthermore, these include the thyroid hormones on the thyroid effects may also be obtained, and LH, FSH and testosterone (OECD, 2009a, 2018). In the present study, we found that oral administration of $100 \mathrm{mg} / \mathrm{kg}$ and $200 \mathrm{mg} / \mathrm{kg}$ of FO for 10 days doesn't have effect on the kidney, liver, and androgen-dependent sex accessory organs, including seimal vesicle, prostate, Cowper's glands, cavernous body of penis, glans penis and adrenal glands in immature male rats. Furthermore, FO has no effect on the serum levels of LH, FSH, and testosterone. Additionally, our result showed that FO does not interact with AR indicating FO does not act as a ligand for AR. To validate the hershberger bioassay and AR competitive binding assay, we used TP and testosterone as a positive control, respectively. Testosterone competitively interacted with AR in vitro assay, and significantly increased the relative weight of androgen-dependent sex accessory tissues and markedly suppressed the serum LH and FSH levels in immature male rats. These results demonstrated that in vitro and in vivo exposure of $\mathrm{FO}$ have non-androgenic effects.

The uterotrophic bioassay (TG 440) was validated by the OECD as a short-term screening test to evaluate the ability of a substance to elicit estrogenic activity (Kanno et al., 2003; OECD, 2009b; Owens \& Koëter, 2003). This is considered the standard method for identification of potential ER agonists that way interfere with ER signaling (Kleinstreuer et al., 2016). The end point measured is an increase in uterine weight caused by ER-mediated water imbibition and cellular proliferation in the uterine tissue (Kleinstreuer et al., 2016; OECD, 2009b). In this validated method, there has been recommended that immature female rats or ovariectomized (OVX) adult female rats can be used, because immature and OVX animals do not produce endogenous estrogens, the uterus becomes sensitive to external estrogenic substances (Billon-Galés et al., 2011; Kleinstreuer et al., 2016). Estrogen is a steroid hormone, and its synthesis and secretion directly inhibit the secretion of the FSH and LH by the pituitary gland (Zhao et al., 2019). In the present study, we investigated the effect of FO on estrogenic activity in vitro and in vivo. Our results showed that oral administration of FO for 3 days doesn't have effect on the relative weight of estrogen-dependent sex accessory organs, including ovaries, vagina, uterus and oviduct in immature female rats. In addition, $\mathrm{FO}$ has no effect on the serum levels of $\mathrm{LH}, \mathrm{FSH}$, and $17 \beta$-estradiol, and does not interact with ER- $\alpha$ and ER- $\beta$. Furthermore, we have verified the $17 \alpha$-EE significantly increased the relative weight of estrogen-dependent sex accessory organs in immature female rats, and $17 \beta$-estradiol strongly interacted with ER- $\alpha$ and ER- $\beta$. Based on these results, we considered that FO have no effect on estrogen activity.

In conclusion, our finding showed that FO does not interact with ER and AR, suggesting consequentially FO does not play as ligand for ER and AR. Furthermore, oral administration of FO did not act as an endocrine disruptor including have androgenic activity, estrogenic activity, and abnormal levels of sex hormone, indicating FO may ensure the safety on endocrine system for development of dietary supplement for bone health.

\section{Competing interests}

No potential conflict of interest relevant to this article was reported.

\section{Funding sources}

This research was part of the project titled "Development of functional food products with natural materials derived from marine resources" funded by the Ministry of Oceans and Fisheries, Korea (grant no.:20170285).

\section{Acknowledgements}

Not applicable.

\section{Availability of data and materials}

Upon reasonable request, the datasets of this study can be available from the corresponding author. 


\section{Ethics approval and consent to participate}

The protocol used this study was reviewed and approved by the Center of Animal Care and Use ethical board of Gachon University (CACU; Approval No.: LCDI-2021-0076).

\section{ORCID}

Hyesook Lee

Hyun Hwangbo

Seon Yeong Ji

Seyeon Oh

Kyung-A Byun

Joung-Hyun Park

Bae-Jin Lee

Gi-Young Kim

Yung Hyun Choi https://orcid.org/0000-0003-3546-9370 https://orcid.org/0000-0003-2180-1205 https://orcid.org/0000-0001-8564-8663 https://orcid.org/0000-0002-3565-7139 https://orcid.org/0000-0001-7486-9137 https://orcid.org/0000-0001-6517-2485 https://orcid.org/0000-0002-5166-5059 https://orcid.org/0000-0002-6878-0790 https://orcid.org/0000-0002-1454-3124

\section{References}

Argente J. Challenges in the management of short stature. Horm Res Paediatr. 2016;85:2-10.

Billon-Galés A, Krust A, Fontaine C, Abot A, Flouriot G, Toutain $\mathrm{C}$, et al. Activation function 2 (AF2) of estrogen receptor- $\alpha$ is required for the atheroprotective action of estradiol but not to accelerate endothelial healing. Proc Natl Acad Sci USA. 2011;108:13311-6.

Calafat AM, Needham LL. Human exposures and body burdens of endocrine-disrupting chemicals. In: Gore AC, editor. Endocrine-disrupting chemicals: from basic research to clinical practice. Totowa, NJ: Humana Press; 2007. p.253-68.

Coringa R, de Sousa EM, Botelho JN, Diniz RS, de Sá JC, da Cruz MCFN, et al. Bone substitute made from a Brazilian oyster shell functions as a fast stimulator for bone-forming cells in an animal model. PLOS ONE. 2018;13:e0198697.

Diamanti-Kandarakis E, Bourguignon JP, Giudice LC, Hauser R, Prins GS, Soto AM, et al. Endocrine-disrupting chemicals: an endocrine society scientific statement. Endocr Rev. 2009;30:293-342.

Dickerson SM, Gore AC. Estrogenic environmental endocrine-disrupting chemical effects on reproductive neuroendocrine function and dysfunction across the life cycle. Rev Endocr Metab Disord. 2007;8:143-59.

Huh K, Nah WH, Xu Y, Park MJ, Gye MC. Effects of recombinant human growth hormone on the onset of puberty, leydig cell differentiation, spermatogenesis and hypothalamic KISS1 expression in immature male rats. World J Mens

Health. 2021;39:381-8.

Ihn HJ, Kim JA, Lim S, Nam SH, Hwang SH, Lim J, et al. Fermented oyster extract prevents ovariectomy-induced bone loss and suppresses osteoclastogenesis. Nutrients. 2019;11:1392.

Jeong A, Park BC, Kim HY, Choi JY, Cheon J, Park JH, et al. Efficacy and safety of fermented oyster extract for height of children with short stature: a randomized placebo-controlled trial. Integr Med Res. 2021;10:100691.

Jeong JW, Choi SH, Han MH, Kim GY, Park C, Hong SH, et al. Protective effects of fermented oyster extract against RANKL-induced osteoclastogenesis through scavenging ROS generation in RAW 264.7 cells. Int J Mol Sci. 2019;20:1439.

Kanno J, Onyon L, Peddada S, Ashby J, Jacob E, Owens W. The OECD program to validate the rat uterotrophic bioassay. Phase 2: dose-response studies. Environ Health Perspect. 2003;111:1530-49.

Kamp GA, Waelkens JJJ, de Muinck Keizer-Schrama SMPF, Delemarre-Van de Waal HA, Verhoeven-Wind L, Zwinderman $\mathrm{AH}$, et al. High dose growth hormone treatment induces acceleration of skeletal maturation and an earlier onset of puberty in children with idiopathic short stature. Arch Dis Child. 2002;87:215-20.

Kleinstreuer NC, Ceger PC, Allen DG, Strickland J, Chang X, Hamm JT, et al. A curated database of rodent uterotrophic bioactivity. Environ Health Perspect. 2016;124:556-62.

Lee H, Hwangbo H, Ji SY, Kim MY, Kim SY, Kim DH, et al. Gamma aminobutyric acid-enriched fermented oyster (Crassostrea gigas) increases the length of the growth plate on the proximal tibia bone in Sprague-Dawley rats. Molecules. 2020a;25:4375.

Lee H, Hwang-Bo H, Ji SY, Kim MY, Kim SY, Woo M, et al. Effect of fermented oyster extract on growth promotion in Sprague-Dawley rats. Integr Med Res. 2020b;9:100412.

Lee YK, Jung SK, Chang YH, Kwak HS. Highly bioavailable nanocalcium from oyster shell for preventing osteoporosis in rats. Int J Food Sci Nutr. 2017;68:931-40.

Molagoda IMN, Karunarathne WAHM, Choi YH, Park EK, Jeon YJ, Lee BJ, et al. Fermented oyster extract promotes osteoblast differentiation by activating the $\mathrm{Wnt} / \beta$-catenin signaling pathway, leading to bone formation. Biomolecules. 2019;9:711.

OECD. Test No. 441: Hershberger bioassay in rats. Paris, France: OECD; 2009a. 
OECD. Test No. 440: Uterotrophic bioassay in rats. Paris, France: OECD; 2009b.

OECD. Hershberger bioassay in rats (H assay) (OECD TG 441) (including OECD GD 115 on the weanling Hershberger bioassay: revised guidance document 150 on standardised test guidelines for evaluating chemicals for endocrine disruption. Paris, France: OECD; 2018. p.463-76.

Owens W, Koëter HBWM. The OECD program to validate the rat uterotrophic bioassay: an overview. Environ Health Perspect. 2003;111:1527-9.

Rosenfeld RG. Insulin-like growth factors and the basis of growth. N Engl J Med. 2003;349:2184-6.

Souza FM, Collett-Solberg PF. Adverse effects of growth hormone replacement therapy in children. Arq Bras Endocrinol Metabol. 2011;55:559-65.

US Environmental Protection Agency. Standard evaluation procedure hershberger assay OCSPP 890.1400. Washington, DC: US Environmental Protection Agency; 2011.

Wit JM, Rekers-Mombarg LTM, Dutch Growth Hormone Advisory Group. Final height gain by GH therapy in children with idiopathic short stature is dose dependent. J Clin Endocrinol Metab. 2002;87:604-11.

Wit JM, Rekers-Mombarg LTM, Cutler GB Jr, Crowe B, Beck TJ, Roberts K, et al. Growth hormone (GH) treatment to final height in children with idiopathic short stature: evidence for a dose effect. J Pediatr. 2005;146:45-53.

Xiang XW, Zheng HZ, Wang R, Chen H, Xiao JX, Zheng B, et al. Ameliorative effects of peptides derived from oyster (Crassostrea gigas) on immunomodulatory function and gut microbiota structure in cyclophosphamide-treated mice. Mar Drugs. 2021;19:456.

Yamasaki K, Sawaki M, Ohta R, Okuda H, Katayama S, Yamada T, et al. OECD validation of the Hershberger assay in Japan: phase 2 dose response of methyltestosterone, vinclozolin, and p,p'-DDE. Environ Health Perspect. 2003;111:1912-9.

Zhao Y, Zheng HX, Xu Y, Lin N. Estrogenic effect of the extract of QingYan formula on reproductive tissues in immature mice. Evid Based Complement Alternat Med. 2019;2019:5493714.

Zhang W, Wei Y, Cao X, Guo K, Wang Q, Xiao X, et al. Enzymatic preparation of Crassostrea oyster peptides and their promoting effect on male hormone production. J Ethnopharmacol. 2021;264:113382. 